\title{
Subject-Specific Tests Improve Master Admission
}

Johanna Hartung, Florian Schmitz, and Oliver Wilhelm

Department of Psychology, Ulm University

\begin{abstract}
Author Note
Johanna Hartung (Dhttps://orcid.org/0000-0002-6392-4468

Florian Schmitz (Dhttps://orcid.org/0000-0001-6368-628X

Oliver Wilhelm (Dhttps://orcid.org/0000-0001-7980-1166

Florian Schmitz is now at the Department of Psychology, University of Duisburg-
\end{abstract} Essen.

We would like to thank our subject matter experts for their support with item generation, employees of the Department of Psychology at Ulm University for their support with test administration, and Verena Friedrich for her support with data preparation.

We have no known conflict of interest to disclose.

Correspondence concerning this article should be addressed to Johanna Hartung, Department of Psychology, Ulm University, Ulm, Germany. E-mail: johanna.hartung@uni$\underline{\text { ulm.de }}$

Draft version 1.1. Please note that this manuscript is currently under review. Please do not copy or cite without authors' permission. 
SUBJECT-SPECIFIC TESTS IMPROVE MASTER ADMISSION

\begin{abstract}
Objective: We investigated the predictive power of bachelor grades and a subject-specific admission test used to select students who enlisted to study in a German master's program in psychology. Methods: Analyses are based on the data of 2,264 university applicants from five cohorts. Results: Bachelor grades were not significantly correlated with master grades as well as with test scores for external applicants, but the relationships were significant for internal applicants. In contrast, the correlation of test scores and master grades was comparable between groups, which can be seen as an indicator of test fairness. Regression analysis showed that the admission test was a valid predictor for master grades. Furthermore, we found that both predictors, bachelor grades and test scores, were incrementally valid. Discussion: In sum, this study illustrates the benefits of using a standardized test for master student admission. We discuss issues of using coherent admission criteria across institutions.
\end{abstract}

Keywords: admission tests, validity, university admission, grades, psychology master 
SUBJECT-SPECIFIC TESTS IMPROVE MASTER ADMISSION

\section{Subject-Specific Tests Improve Master Admission}

Admission to the limited places of most Master's programs is based on meritocracy: students, who have been successful in their undergraduate program get accepted into the graduate program (Perfetto et al., 1999). Suitable admissions criteria are essential for admission-restricted programs. A considerable proportion of the literature on college admission focuses on undergraduate programs (Formazin et al., 2011; Hell, Linsner, et al., 2008) or the Graduate Record Examination for graduate student admission (Schwager et al., 2015) and the U.S. American educational sector (Kuncel et al., 2001; Kuncel \& Hezlett, 2010). Conversely, empirical results on the prognostic validity of admission criteria for consecutive master programs in Germany are sparse. The aim of the current article is to investigate the applicability of combined bachelor grades or undergraduate grade point average (U-GPA) and subject-specific test results to predict study success for a master's in psychology program at a German university.

The utility of an admission instrument is mainly judged and determined by its predictive value. Most often, student admission instruments are evaluated by how well they predict grades. Grades are usually comprehended as measure of college success and are the most prevalent validation criteria. They can be retrieved and verified relatively easily (Hell et al., 2007). Grades reflect mainly cognitive abilities such as domain specific knowledge and general abilities and skills, but they also capture non-cognitive characteristics such as achievement motivation or learning effort (Camara et al., 2003).

The most commonly used admission criteria is the bachelor grade, which was found to be predictive of graduate student performance (Kuncel et al., 2001, 2007; Kuncel \& Hezlett, 2007; Troche et al., 2014). Completed bachelor degrees are a prerequisite for admission into master programs. Grades of these degrees are an intrinsic part of the admission formalities. Nevertheless, the main problem that most admission-restricted master programs face is that U-GPAs cannot be compared easily across universities and degrees (Hell, Trapmann, et al., 
SUBJECT-SPECIFIC TESTS IMPROVE MASTER ADMISSION

2008; Weimar et al., 2017). Additionally, it is known that grades in psychology bachelor programs are highly skewed (Antoni, 2019). The general tendency towards low variability in grades leads to reduced predictive power.

Studies in different fields generally show that standardized tests are incrementally predictive of performance in graduate programs over and above undergraduate grade point averages (Kuncel \& Hezlett, 2007, 2010; Zwick, 2002). The purpose of these tests is to identify the most promising master students despite disparate educational backgrounds. In the context of highly selective undergraduate psychology programs, subject-specific tests capturing prior knowledge can be expected to have higher predictive validity relative to general cognitive ability tests (Formazin et al., 2011; Kuncel et al., 2001; Kunina et al., 2007).

However, the utility of standardized test scores for admission varies. In general, the utility of an admission test is higher, 1) the higher the validity, 2) the more selective the process, 3) the higher the proportion of qualified applicants, and 4) the more relevant the differences in outcome variables (Taylor \& Russell, 1939).

The German tertiary educational system comprises different types of higher education institutions that differ in how selective they are, but also in their grading standards (Hell, Trapmann, et al., 2008; Weimar et al., 2017). The two types of higher education institutions that are of interest for the current investigation are universities and universities of applied sciences (Fachhochschulen, FH). The focus of Bachelor's programs at universities is more on science while FHs have a stronger focus on practical and applied issues. Universities are more selective (Heublein, 2014). Students from all types of higher education institutions can apply to the master's program in focus of the current investigation and were treated equally in the application process.

The current study investigates the validity of a subject-specific test for selecting psychology master students at a German university. The incremental validity of both predictors will be estimated in a multiple regression analysis with master grades or graduate 
SUBJECT-SPECIFIC TESTS IMPROVE MASTER ADMISSION

grade point averages (G-GPA) as the dependent variable. Group differences in grades, test results and predictive validity will be illustrated. The aim of this investigation is to inform decisions on selection processes based on empirical investigations.

\section{Methods}

\section{Sample}

The database for this study was assembled from the master admission process at Ulm University from 2012 until 2016, comprising 2264 applicants and 425 enrolled master students in total. Nearly all students from these cohorts have finished their degree at the time of data analysis. Hence, almost complete data on G-GPAs are available for these cohorts.

\section{Figure 1}

Number of Students for Each Step of the Application Process

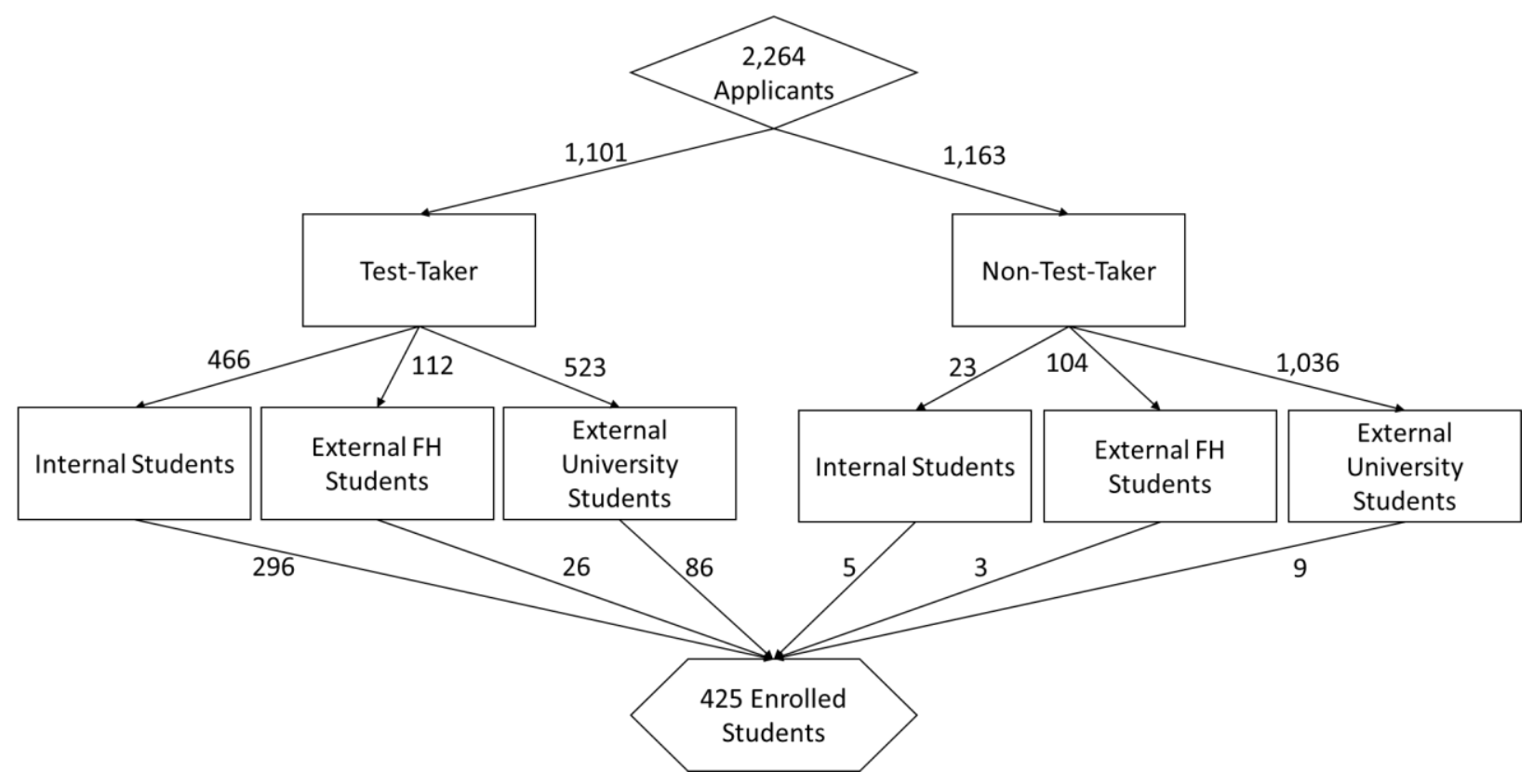

Note. $\mathrm{FH}=$ Fachhochschule or universities of applied sciences.

\section{Grading System}

At German universities, the academic grading system consists of a scale from 1 to 5 with 1.0-1.5 being "very good" (corresponds to an A in the U.S. grading system), 1.6-2.5 being "good" (B), 2.6-3.5 being "satisfactory" (C), 3.6-4.0 being "sufficient" (D) and 5.0 
SUBJECT-SPECIFIC TESTS IMPROVE MASTER ADMISSION

being "not sufficient" or "failed" (F). Thus, lower grades indicate higher achievements.

Psychology programs in Germany are characterized by a tendency towards good grades and a lack of exhausting the range of the grading scale. The strength of this tendency varies across universities (Antoni, 2019) and is stronger in master than in bachelor programs.

\section{Admission Test}

Test participation was voluntary; however, applicants were encouraged to take the admission test in order to increase their chance of being accepted for the Masters' program at Ulm University. A 20 Euro fee was charged for test participation. Information on the admission process and on the test was accessible for potential candidates on the website of the institute. The paper-pencil test was administered by employees of the Psychology Department at Ulm University. Test-takers had 120 minutes to answer 100 single-choice items with four response alternatives each. Participants earned one point for each correctly solved item. The admission test was based on the bachelor curriculum at Ulm University, which conforms to the recommendations of the German Association for Psychology (DGPs). The number of questions for each subject / area was proportional to the European Credit Transfer System (ECTS) points of the respective modules at Ulm University (see Table 1 for example questions). Additionally, questions are based on descriptions in the handbook of modules (which can be retrieved from the website, and is available to external applicants). To ensure content validity, the questions cover a wide range of topics from the syllabus that has been approved by the German Association for Psychology (DGPs). Items were developed by the professors of the respective areas (e.g., Methods, Clinical, Educational, etc.) at Ulm University in line with these recommendations. Every year, $20 \%$ of items are completely exchanged, while psychometrically challenging items within areas are exchanged preferentially and minor modifications such as item wording and the order of responses were exchanged in a number of additional questions. About $49 \%$ of all applicants took the test in 
SUBJECT-SPECIFIC TESTS IMPROVE MASTER ADMISSION

the years from 2012 to 2016 (see Figure 1), while the proportion of test-takers in the group of enrolled students was $96 \%$.

\section{Table 1}

\section{Example questions}

\begin{tabular}{l|l}
\hline $\begin{array}{l}\text { What is a disadvantage of dichotomizing } \\
\text { continuous variables? }\end{array}$ & $\begin{array}{l}\text { When two stimuli are presented in } \\
\text { short succession, the first may affect }\end{array}$ \\
$\begin{array}{ll}\text { a) The real relation will be overestimated } & \text { perception or processing of the second } \\
\text { b) The correlation cannot be estimated } & \text { stimulus. This effect is known as... } \\
\text { c) Even with small samples correlations } & \text { a) Learning } \\
\text { are almost always significant } & \text { b) Shifting } \\
\text { d) The real relation will be } & \text { c) Priming } \\
& \text { d) Binding }\end{array}$
\end{tabular}

\section{Scoring and Admission}

Applicants needed to have an average U-GPA of 2.6 or better to be considered in the application process. The admission decision was based on the joint rank of U-GPA and admission test score. Both criteria were ranked in ascending order. The worst grade was ranked 1 for U-GPAs. Applicants, who did not take the test, were ranked 1 for the test. This procedure leads to nearly continuous ranks for U-GPAs, but there is a gap between ranks for applicants without test and with test corresponding to the number of applicants, who did not take the test. The final ranking was computed with a 55\% weight for the bachelor's grade rank and a $45 \%$ weight for the test rank order, thereby weighting the U-GPA slightly more than the result of the admission test. As not all students, who were offered a place, took it, there can be multiple rounds of admission in which students with increasingly lower ranks will be admitted and potentially enrolled into the program. 
SUBJECT-SPECIFIC TESTS IMPROVE MASTER ADMISSION

\section{Data analysis}

G-GPAs for 425 students were retrieved. Fewer than five grades were available for 44 students at the time of data analyses and these participants were excluded from further analysis. Fifty-three candidates took the test twice, and two participants took the test three times (corresponding with a total of $2 \%$ of all test-takers) ${ }^{1}$. Because the individual cohorts are too small to get robust estimates for each cohort, only pooled data were analyzed. We compared three groups: internal applicants, external applicants from FHs (private and public), and external applicants from universities (including Germany's State Distance-Learning University). However, group sizes were too small for this covariate, too, to warrant regression analysis with G-GPAs as the dependent variable separately for each group, which is why external applicants were pooled for this analysis.

\section{Results}

\section{Descriptive Statistics}

\section{Overall sample}

On average, test-takers answered about 54\% $(S D=16)$ of the questions in the subject test correctly. As a result of the selection process, students who were (later) enrolled in the Master's program had received U-GPAs about a third of a standard deviation better than not enrolled applicants, and they achieved nearly one standard deviation better results on the admission test on average (see Table 2). As expected, G-GPAs were highly skewed with, most students having an average G-GPA better than 2.0.

\footnotetext{
${ }^{1}$ For analyses based on enrolled students, only one test performance from the year when they were accepted used. In analyses based on all applicants, they were included multiple times as they were in the application process multiple times.
} 
SUBJECT-SPECIFIC TESTS IMPROVE MASTER ADMISSION

Table 2

Descriptive statistics for enrolled and not enrolled applicants

\begin{tabular}{lccccc}
\hline & $N$ & Mean & $S D$ & range & $d$ \\
\hline U-GPA - not enrolled & 1,893 & 1.83 & 0.39 & $1.0-2.9$ & 0.33 \\
U-GPA - enrolled & 425 & 1.72 & 0.26 & $1.1-2.6$ & \\
\hline Admission test scores- not enrolled & 740 & 49.80 & 14.15 & $5-89$ & -0.93 \\
Admission test scores- enrolled & 408 & 63.19 & 14.65 & $26-90$ & \\
& & & & & \\
\hline G-GPA & 381 & 1.62 & 0.33 & $1.05-3.40$ &
\end{tabular}

Notes. $S D=$ standard deviation, $d=$ Cohen's $d$ for the group difference between enrolled and not-enrolled students. U-GPA = undergraduate grade point average. G-GPA = graduate grade point average. GPAs are based on the following grading system: 1.0-1.5 being "very good" (corresponds to an A in the U.S. grading system), 1.6-2.5 being "good" (B), 2.6-3.5 being "satisfactory" (C), 3.6-4.0 being "sufficient" (D) and 5.0 being "not sufficient" or "failed" (F)

\section{Differences Between Different Types of Higher Education Institutions:}

U-GPAs. An ANOVA indicated that there were group differences in U-GPAs between different types of higher education institutions $\left(\mathrm{F}(2,2261)=18.33, p<.01, \eta^{2}=.02\right.$; see Figure 2). The Tukey Honest test, for performing multiple pairwise-comparison between the means of groups, showed that the differences between external applicants from universities and FHs $(p<.01, d=0.40)$, and from internal applicants and external FH applicants $(p<.01$, $d=0.32$ ) were significant after Bonferroni adjustment. U-GPAs from external FH applicants were significantly better than from external university and internal applicants. Applicants' UGPAs for internal applicants and external university applicants differ slightly with internal applicants having grades that are .05 better on average than external university applicants $(p=$ $.01, d=.15)$. 


\section{Figure 2}

Undergraduate Grade Point Average (U-GPA) of Applicants from Different Types of Higher

\section{Education Institutions}

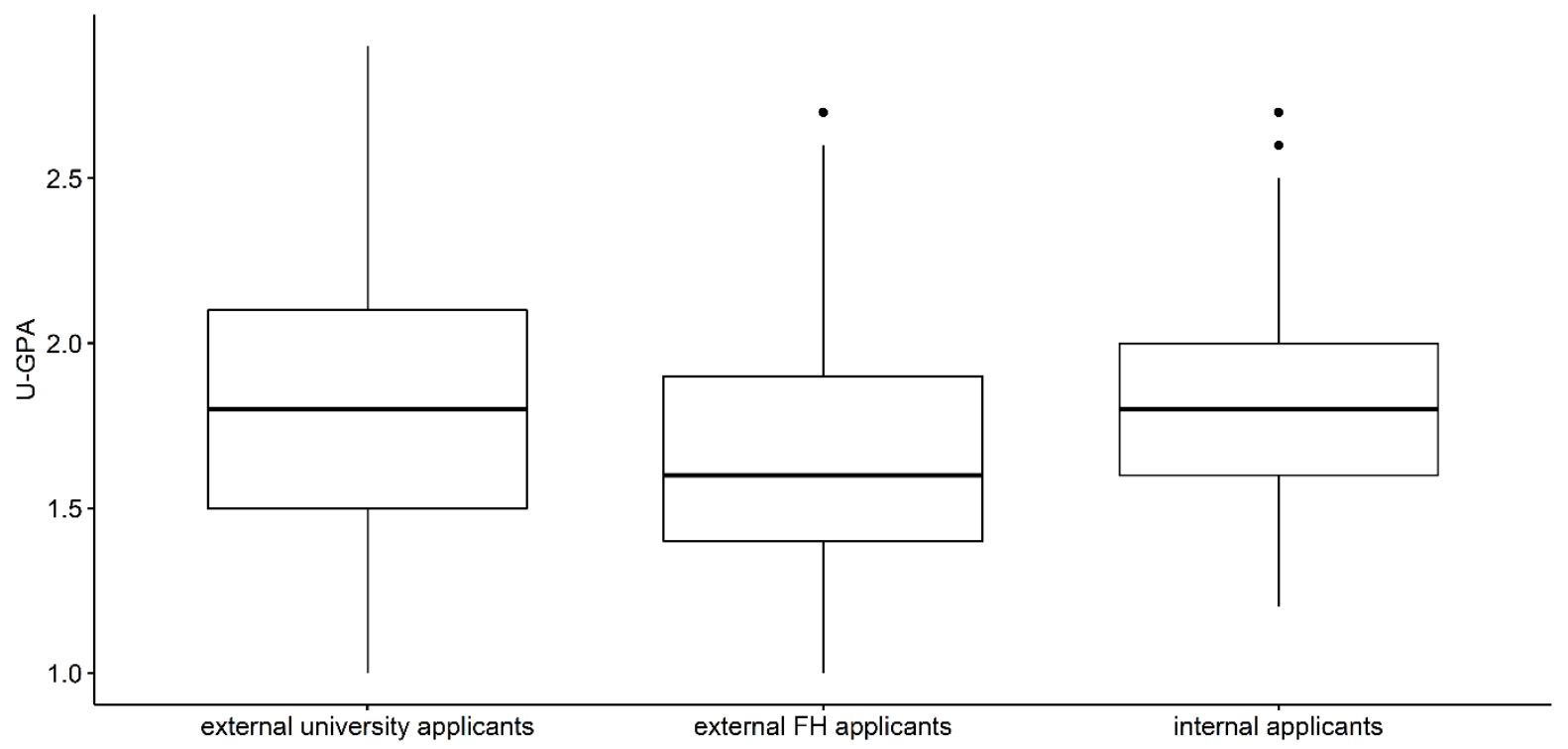

Note FH $=$ Fachhochschule or university of applied sciences. The line across the box represents the median. The box ranges from the lower to the upper quartile. $n_{\text {external university applicants }}=1,559, n_{\text {external } \mathrm{FH} \text { applicants }}=216$, $n_{\text {internal applicants }}=489$.

Admission Test Scores. Applicants with bachelor degrees from different types of higher education institutions differed in their test performance, as depicted in Figure 3 and as confirmed in an ANOVA $\left(\mathrm{F}(2,1098)=1145, p<.01, \eta^{2}=.68\right)$. More specifically, all differences were significant $(p<.01)$ based on a Tukey HSD with Bonferroni correction. First, internal applicants performed better than both other groups $\left(d_{\mathrm{Uni}}=2.58, d_{\mathrm{FH}}=3.51\right)$. Second, external FH applicants performed significantly poorer on the test than both other groups $\left(d_{\text {external }}=1.23\right)$. 
SUBJECT-SPECIFIC TESTS IMPROVE MASTER ADMISSION

\section{Figure 3}

Admission Test Score of Applicants from Different Higher Education Institution Types

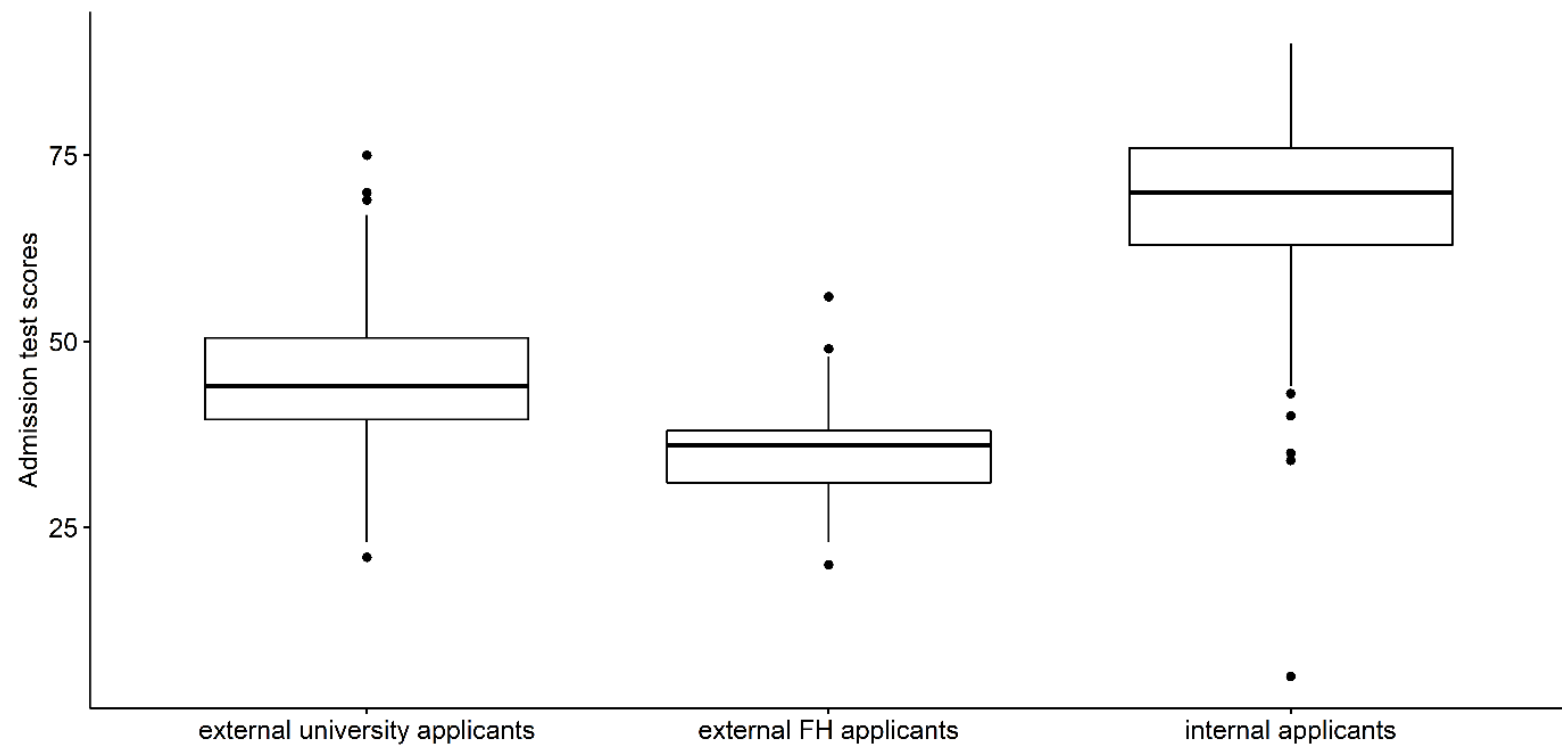

Note $\mathrm{FH}=$ Fachhochschule or university of applied sciences. $n_{\text {external university applicants }}=523, n_{\text {external } \mathrm{FH}}$ applicants $=112, n_{\text {internal } \text { applicants }}=466$.

G-GPAs. Students, who received their Bachelor's degree at different types of higher education institutions differ in their academic achievement in the master's program $(\mathrm{F}(2,378)$ $\left.=19.42, p<.01, \eta^{2}=.09\right)$. Based on a Tukey HSD with Bonferroni correction, students coming from a FH, had worse G-GPAs than students from universities on average (all universities vs. FH, $\left.p<.01, d_{\text {external }}=0.77, d_{\text {internal }}=1.17\right)$. The comparison of internal and external university students was not significant $(p=.05, d=0.31)$, indicating that students, who received their Bachelor's degree at any other higher education institution type than FH show a similar academic performance in the master's program (see Figure 4). 


\section{Figure 4}

Graduate Grade Point Average (G-GPA) of students from Different Higher Education Institution Types

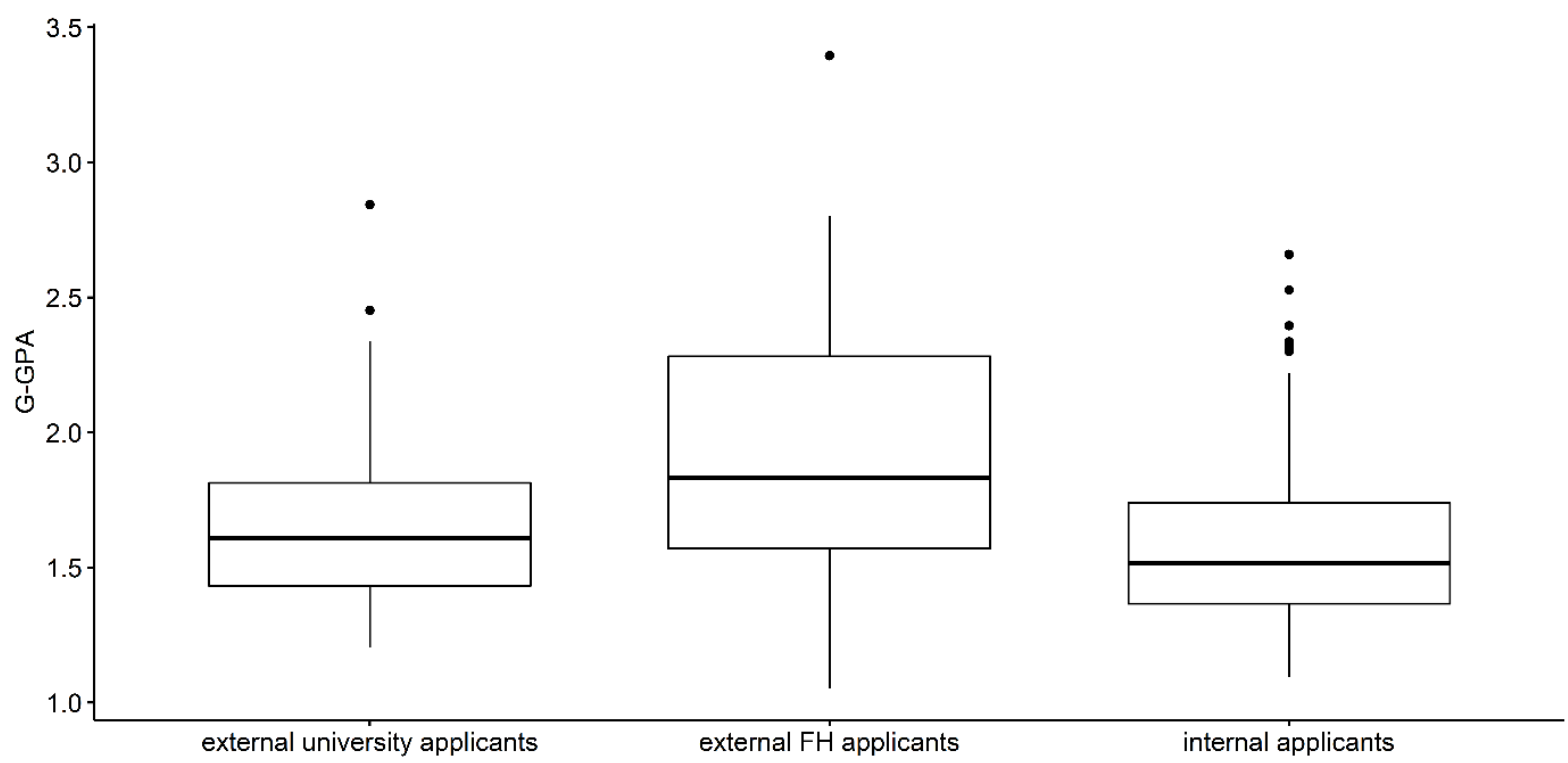

Note. $\mathrm{FH}=$ Fachhochschule or university of applied sciences. $n_{\text {external university applicants }}=91, n_{\text {external FH applicants }}$ $=29, n_{\text {internal applicants }}=261$.

\section{Correlations}

\section{Overall sample}

\section{Table 3}

Correlation of U-GPA, admission test scores, and G-GPA for all enrolled test-takers/ internal/ external applicants

\begin{tabular}{lllllll}
\hline & $\begin{array}{l}\text { All } \\
\text { enrolled } \\
\text { test-takers }\end{array}$ & $\begin{array}{l}\text { Internal } \\
\text { applicants }\end{array}$ & $\begin{array}{l}\text { External } \\
\text { applicants }\end{array}$ & $\begin{array}{l}\text { All } \\
\text { enrolled } \\
\text { test-takers }\end{array}$ & $\begin{array}{l}\text { Internal } \\
\text { applicants }\end{array}$ & $\begin{array}{l}\text { External } \\
\text { applicants }\end{array}$ \\
\hline U-GPA & & & Admission test scores & \\
\hline $\begin{array}{l}\text { Admission } \\
\text { test scores }\end{array}$ & $.01(.87)$ & $-.40(<.01)^{1}$ & $.02(.86)^{2}$ & & & \\
G-GPA & $.29(<.01)$ & $.50(<.01)^{3}$ & $.20(.03)^{4}$ & $-.42(<.01)$ & $-.38(<.01)^{5}$ & $-.34(<.01)^{6}$ \\
\hline
\end{tabular}

Note. $p$ values in brackets. The correlation between U-GPA and admission test scores for all master students (including the ones who did not take the test) has the same strength. ${ }^{1} N=296 ;{ }^{2} N=112 ;{ }^{3} N=261 ;{ }^{4} N=120 ;{ }^{5} N$ $=259 ;{ }^{6} N=110$. 


\section{SUBJECT-SPECIFIC TESTS IMPROVE MASTER ADMISSION}

For the subsample of students, who took the test and have been enrolled, U-GPA and test results were not correlated (see Table 3). The correlation between U-GPA and admission test scores for all applicants was $r=-.28(p<.01)$. The correlations of the admission criteria with G-GPAs were moderately high.

\section{Differences between Internal and External Students}

The correlation between bachelor and G-GPAs for internal students, was $r=.50(p<$ $.01)$, while it was $r=.20(p=.03)$ for external students (see Table 3). The correlations in the two subsamples differed significantly from each other $(\mathrm{z}=3.11, p<.01)$. The correlation between U-GPA and admission test scores also differed significantly for these groups $(\mathrm{z}=$ $3.78, p<.01$ ), showing no significant relationship for external students, but associating better U-GPAs with better test performance for internal students. The correlation between admission test scores and G-GPAs was found to be about the same in both groups $(\mathrm{z}=0.40, p=.69)$.

\section{Incremental validity}

\section{Overall sample}

Next, we turn to the question of how much variance in G-GPAs can be explained by U-GPAs and admission test scores. For the subset of participants who both took the test, and for whom Master's grades were available $(n=335)$, a regression analysis was performed (see Table 4). Model 1 revealed that the U-GPA was a significant predictor of the G-GPA in this sample. It explained about $8 \%$ of the variance. Model 2 used admission test scores as a single predictor of G-GPAs. Test-takers achieved about .42 standard deviations better grades per standard deviation on the test. To test the incremental validity of the predictors, Model 3 used both predictors. U-GPAs and admission test scores were both significant predictors and explained about $26 \%$ of the variance in G-GPAs. 
SUBJECT-SPECIFIC TESTS IMPROVE MASTER ADMISSION

\section{Table 4}

Regression Analysis Predicting Average G-GPA

\begin{tabular}{lllllll}
\hline Model & predictor & $\beta$ & $t$ & $p$ & $R^{2}$ & adjusted $R^{2}$ \\
\hline 1 & U-GPA & 0.29 & 5.87 & $<0.01$ & .09 & .08 \\
2 & Admission test & -0.42 & -8.83 & $<0.01$ & .18 & .17 \\
& & & & & & \\
& scores & & & & & \\
& U-GPA \& & 0.30 & 6.61 & $<0.01$ & .26 & .26 \\
& Admission test & -0.42 & -9.39 & $<0.01$ & & \\
& scores & & & & & \\
\hline
\end{tabular}

\section{Differences between Internal and External Applicants}

The regression analyses to investigate the predictive validity of the two admission criteria for the two subsamples of internal and external applicants showed a slightly different pattern (see Table 5). While test performance was a significant predictor of G-GPAs in both subsamples, the U-GPA predicted the G-GPA only in the subgroup of internal students. This was the case in the models with the single predictors as well as the model including both predictors. Correspondingly, the explained variance was considerably larger for internal students than for external students $\left(R^{2}=.28\right.$ vs. $\left.R^{2}=.13\right)$. When U-GPA is the only predictor, intercepts differ between the two subsamples. The difference in intercepts for the admission test scores is rather small and statistically not significant. 
SUBJECT-SPECIFIC TESTS IMPROVE MASTER ADMISSION

\section{Table 5}

Regression Analysis Predicting Average G-GPA, split for internal / external applicants

\begin{tabular}{llllllll}
\hline Model & predictor & Intercept (SE) & $\beta$ & $t$ & $p$ & $R^{2}$ & adjusted $R^{2}$ \\
\hline 1 & U-GPA & $50.97(11.37) / 124.59(21.69)$ & $.53 / .20$ & $9.38 / 2.24$ & $<0.01 / .03$ & $.25 / .04$ & $.25 / .03$ \\
2 & Admission test scores & $243.56(13.37) / 236.82(16.78)$ & $-.38 /-.34$ & $-6.57 /-3.75$ & $<0.01 /<0.01$ & $.14 / .12$ & $.14 / .11$ \\
3 & U-GPA \& & $126.16(20.51) / 196.69(27.63)$ & $.42 / .17$ & $7.13 / 1.82$ & $<0.01 / .07$ & $.29 / .14$ & $.28 / .13$ \\
& Admission test scores & & $-.23 /-.34$ & $-4.11 /-3.80$ & $<0.01 /<0.01$ & & \\
\hline
\end{tabular}




\section{SUBJECT-SPECIFIC TESTS IMPROVE MASTER ADMISSION}

\section{Discussion}

The results of the current analysis support and extend previous evidence of the incremental validity of standardized admission tests over and above the U-GPA. Moreover, in the subgroup of external applicants, the admission test was the only significant predictor of GGPAs.

There was a significant correlation between admission test scores and U-GPAs for internal applicants but not for external ones or the sample including all applicants. The test is supposed to measure knowledge that should have been acquired by learning opportunities during the Bachelor's program. Likewise, the U-GPAs are believed to be indicative of the acquired knowledge and competencies in the Bachelor's program. Therefore, one could have expected that applicants with better U-GPAs show better performance on the test on average. However, this was not the case. One possible explanation might be that the test covers contents only taught at Ulm University but not at other institutes. However, the test content was based on recommendations of the national psychological association (DGPs). Furthermore, the test represents the knowledge deemed a prerequisite for the Master's program at Ulm University.

Another possible explanation could be grading policies at different types of higher education institutions. As already discussed in the Introduction, there is some evidence that different grading cultures exist at different institutes (Hell, Trapmann, et al., 2008; Weimar et al., 2017). Breaking the U-GPAs by type of higher education institution, it turned out that students from FHs had significantly better grades than students from universities. Given nationally the reverse is true (poorer grades at FHs) (Antoni, 2019) there must be selfselection effects of non-trivial magnitude. The opposite was found for G-GPAs of enrolled students. External FH applicants had significantly worse grades. Nevertheless, group differences in test results are corresponding to the group differences in G-GPAs with external 


\section{SUBJECT-SPECIFIC TESTS IMPROVE MASTER ADMISSION}

FH applicants performing poorer on the admission test and - if enrolled - achieving worse grades during the master's program.

Differences in acquired knowledge or general cognitive abilities could also contribute to the observed differences, but this hypothesis cannot be tested with the available data. Specifically, there could be an admission bias reflecting that students with better grades in school were more likely to get enrolled into university programs while students with worse grades might have fallen back on less selective programs, like FHs (Ramm et al., 2014). It is known that a better secondary school level grade still predicts better grades on the Master's level (Trapmann et al., 2007). Lower drop-out rates at FHs (Heublein, 2014), academically weaker students (based on their college entrance grades) with simultaneously better U-GPAs are indicative for lower educational standards in FH Bachelor's programs.

Internal applicants showed by far the best performance on the test. This difference in performance could have several overlapping causes and cannot be investigated separately in the current study. For instance, one reason could be test preparation. Most students apply for the Master's program at the university where they have done their Bachelor's. Students might favor to stay at the same university due to familiarity with the program, friends, housing or other reasons. For external students the new university might only be a fallback option, which could also contribute to the differences in the proportion of test-takers. Thus, the motivation of internal applicants is potentially higher leading to higher effort in test preparation.

Furthermore, it is easier for internal applicants to build study groups for test preparation as most of their classmates will also take the test while external students might be the only ones of their institution applying for the program in Ulm. Additionally, students, who predict their chances of getting into the Master's program of another university to be high might not take the test at all or invest little effort on the test in Ulm. It is likely, too, that students who did not well at their previous universities were more likely to apply in Ulm and at other universities to 


\section{SUBJECT-SPECIFIC TESTS IMPROVE MASTER ADMISSION}

expand their possibilities to continue their studies. Conversely, strong students who consider their acceptance at their own university as almost safe may be less likely to apply at other places. Of course, other biases (e.g., content bias or other test biases) favoring internal students cannot be ruled out in the current investigation. To examine this issue further, future studies could test differential item functioning in the admissions test between internal and external applicants. Additionally, studies investigating students' application motivations and strategies could yield some insight into self-selection and recruiting biases.

The results have clear implications. A position favoring the use of bachelor grades and renouncing the use of tests will deliver poor decisions. Whereas the decrement in $\mathrm{R}^{2}$ relative to the use of both predictors is substantial for internal applicants it is devastating for external applicants. A position favoring the use of both predictors on the other side will yield valid decisions, albeit the validity is limited in the external group. Clearly, restriction of range is a difficult topic and apparently more so in the opaquer group of external applicants.

Based on the criteria discussed in the Introduction, we can conclude the following for the admission process for the Master's program in Psychology at Ulm University: (1) is selective, (2) is improved by adding tests as predictors, (3) shows relevant variation in criterion performance.

(1) The process is highly selective as less than $20 \%$ of applicants got enrolled into the master's program in the cohorts of applicants from 2012 to 2016 . Further, as the number of applicants increases continuously (e.g., 140 applications more in 2017 compared to 2016 for the same number of places), the admission test becomes increasingly more selective. In 2018 and 2019 only applicants, who participated in the admission test were admitted, which underscores the importance of the test in the admission process.

(2) Test score as well as U-GPA were valid predictors of G-GPAs. The validity of the admission test and the U-GPA is underestimated, because its correlation with the G-GPA is 
SUBJECT-SPECIFIC TESTS IMPROVE MASTER ADMISSION

only based on the sub-group of admitted applicants, resulting in range restrictions.

Consequently, reduced variability in grades reduces also predictive power in the admissions context. Furthermore, standards in grading vary a lot between universities, which raises the question of comparability of grades from different universities.

Test fairness is often described as the comparability of regression weights in different groups. While the U-GPA did not correlate significantly with the G-GPAs for external applicants, it correlated significantly in the subsample of internal applicants. Contrarily, the correlation of test scores with G-GPAs was approximately the same in both groups. This result can be interpreted as indicative for the superiority of the test, in comparison to grades, with relation to fairness as an admission criterion.

Potentially, a positive relationship between U-GPA and admission test scores exists within the subgroups of applicants from a specific higher education institution. Unfortunately, the sample sizes were too small to analyze the data with specific institution as a multi-level variable. If a national solution for the master admission would be applied, sample sizes would be large enough to estimate institution-specific correlations between U-GPA and admission test score and to investigate the effect of institutions. Additionally, the quite heterogenous group of external applicants could be broken down further.

(3) Only grades were used as a criterion in this study, while study success could be operationalized in alternative ways. In fact, it was argued (Gillespie et al., 2002) that grades only reflect a small proportion of what is considered successful completion of a degree. Another often used criterion are drop-out rates. However, completion rates in our study were at the ceiling, and hence, lacking the variability necessary for a sensitive criterion.

A prospective but difficult to assess criterion would be occupational success. However, data was not available in the present study and establishing comparable rating 
SUBJECT-SPECIFIC TESTS IMPROVE MASTER ADMISSION

standards for dissimilar occupations is generally difficult. Conclusively, G-GPAs are a feasible and easily to retrieve indicator of study success.

\section{Limitations}

The reality behind the data used for the current investigation is complex. There are applicants for whom no test scores were available including students who got enrolled and ones who did not. Furthermore, parts of the self-selection mechanisms are unknown: who decided to apply for the program (e.g., is this decision dependent on U-GPA?), who choose to skip the test, how were applications at other institutions proceeding (i.e., do applicants have to decide where to enroll at different time points), etc.

The nature of the data enforces that results are based on the group of students who enrolled in the Master's program. The restriction of range in the criterion as well as the predictors probably leads to an underestimation of predicted validity. Furthermore, it is unclear on which other variables enrolled students might differ from students who were not accepted or decided to not enroll.

The restriction to grades as validation criterion is a mono-trait-mono-method problem of grades as admission predictor and validation criterion. Predicting grades with grades (this applies especially to internal applicants, who were probably graded by the same lecturers) might lead to an overestimation due to a mono-method effect. Alternatively or additionally, a master knowledge test could be used to measure the acquired knowledge at the end of the program. Other things being equal, using more diverse methods to capture predictor and criteria would be very helpful to understand both spheres much better.

Lastly, the current investigation is based on data from a single institution. It is unclear if results generalize to other institutions with different Master's programs. However, there are two main arguments indicating that the current findings can be generalized. The first 
SUBJECT-SPECIFIC TESTS IMPROVE MASTER ADMISSION

argument is that the admission test covers content that is deemed to be must-have Bachelor knowledge by national recommendations (DGPs) and thus the prerequisite for most Master's programs. Nevertheless, comparing module handbooks across institutes could provide some insight whether students from universities with curriculums closer to the one in Ulm perform better than students from institutes with more divergent curriculums. The second argument concerns the comparability of U-GPAs. As grading policies at different institutions vary widely - which is evident by the distribution of U-GPAs across institutions, but more importantly might mask different educational standards - the validity of U-GPAs as an admission criterion must be questioned. Using standardized admission tests that require basic knowledge necessary for the Master's program circumvent these problems. Tackling the problem from an additional angle, it might be generally helpful if Bachelor as well as Master certificates would include the rank a person achieved within the institute to provide at least some orientation on their relative performance.

\section{Implications and Conclusion}

The results have implications that are relevant for psychology master student admission in Germany. Admitting students solely based on U-GPAs favors students from institutes with a more lenient grading policy. The emphasis on U-GPAs contributes to students' focus on grades rather than knowledge acquisition. Furthermore, universities are incentivized loosening their grading policies to achieve better ratings, attract more applicants, and thus gain an advantage in the competition between universities. Most importantly, a subject-specific knowledge test can help identify promising students, especially students coming from other institutions.

Using institute-specific tests introduces an additional burden for applicants (i.e. travel expenses and test preparation). A standardized test on the national level based on recommendations for must-have Bachelor knowledge could increase fairness in admission 
SUBJECT-SPECIFIC TESTS IMPROVE MASTER ADMISSION

procedures. It would help institutions to admit as many qualified students as possible and help save resources. Moreover, a standardized nationwide application process would facilitate applications for students, who at the moment either have to trust that their U-GPA is comparatively good or take multiple admission tests that vary in content and costs.

In summary, the current study provides informative insights about student admission for Master's programs. We conclude that the admission test provides significant, incremental, predictive validity beyond U-GPAs. We recommend using standardized subject-specific tests for the admission of Master's students in Psychology.

\section{References}

Antoni, C. H. (2019). Zur Lage der Psychologie. Psychologische Rundschau, 70(1), 4-26. https://doi.org/10.1026/0033-3042/a000429

Camara, W., Kimmel, E., Scheuneman, J., \& Sawtell, E. A. (2003). Whose grades are inflated. The College Board, New York.

Formazin, M., Schroeders, U., Köller, O., Wilhelm, O., \& Westmeyer, H. (2011). Studierendenauswahl im Fach Psychologie. Psychologische Rundschau, 62(4), 221236. https://doi.org/10.1026/0033-3042/a000093

Gillespie, M., Kim, B., Oswald, F., Ramsay, L., \& Schmitt, N. (2002). Biodata and situational judgment inventories as measures of college success: Developing and pilot testing phases. Interim report available from The College Board, New York.

Hell, B., Linsner, M., \& Kurz, G. (2008). Prognose des Studienerfolgs. In M. Rentschler \& H.-P. Voss (Hrsg.), Studieneignung und Studierendenauswahl (S. 132-177). Shaker Verlag. https://kops.uni-konstanz.de/handle/123456789/10609

Hell, B., Trapmann, S., \& Schuler, H. (2008). Synopse der Hohenheimer Metaanalysen zur Prognostizierbarkeit des Studienerfolgs und Implikationen für die Auswahl- und Beratungspraxis. In H. Schuler \& B. Hell (Hrsg.), Studierendenauswahl und 


\section{SUBJECT-SPECIFIC TESTS IMPROVE MASTER ADMISSION}

Studienentscheidung (S. 43-54). Hogrefe. https://kops.uni-

konstanz.de/handle/123456789/11049

Hell, B., Trapmann, S., Weigand, S., \& Schuler, H. (2007). Die Validität von

Auswahlgesprächen im Rahmen der Hochschulzulassung-eine Metaanalyse.

Psychologische Rundschau, 58(2), 93-102. https://doi.org/10.1026/0033-3042.58.2.93

Heublein, U. (2014). Student Drop-out from G erman Higher Education Institutions.

European Journal of Education, 49(4), 497-513. https://doi.org/10.1111/ejed.12097

Kuncel, N. R., Credé, M., \& Thomas, L. L. (2007). A Meta-Analysis of the Predictive Validity of the Graduate Management Admission Test (GMAT) and Undergraduate Grade Point Average (UGPA) for Graduate Student Academic Performance. Academy of Management Learning \& Education, 6(1), 51-68.

https://doi.org/10.5465/amle.2007.24401702

Kuncel, N. R., \& Hezlett, S. A. (2007). Standardized tests predict graduate students' success. Science, 315(5815), 1080-1081. https://doi.org/10.1126/science.1136618

Kuncel, N. R., \& Hezlett, S. A. (2010). Fact and fiction in cognitive ability testing for admissions and hiring decisions. Current Directions in Psychological Science, 19(6), 339-345. https://doi.org/10.1177/0963721410389459

Kuncel, N. R., Hezlett, S. A., \& Ones, D. S. (2001). A comprehensive meta-analysis of the predictive validity of the graduate record examinations: Implications for graduate student selection and performance. Psychological bulletin, 127(1), 162-181. https://doi.org/10.1037/0033-2909.127.1.162

Kunina, O., Wilhelm, O., Formazin, M., Jonkmann, K., \& Schroeders, U. (2007). Extended criteria and predictors in college admission: Exploring the structure of study success and investigating the validity of domain knowledge. Psychology Science, 49(2), 88114. 
SUBJECT-SPECIFIC TESTS IMPROVE MASTER ADMISSION

Perfetto, G., Escandón, M., Graff, S., Rigol, G., \& Schmidt, A. (1999). Toward a Taxonomy of the Admissions Decision-Making Process: A Public Document Based on the First and Second College Board Conferences on Admissions Models. College Entrance Examination Board.

Ramm, M., Multrus, F., Bargel, T., \& Schmidt, M. (2014). Studiensituation und studentische Orientierungen: 12. Studierendensurvey an Universitäten und Fachhochschulen (Langfassung).

Schwager, I. T. L., Hülsheger, U. R., Bridgeman, B., \& Lang, J. W. B. (2015). Graduate Student Selection: Graduate record examination, socioeconomic status, and undergraduate grade point average as predictors of study success in a western European University. International Journal of Selection and Assessment, 23(1), 7179. https://doi.org/10.1111/ijsa.12096

Taylor, H. C., \& Russell, J. T. (1939). The relationship of validity coefficients to the practical effectiveness of tests in selection: Discussion and tables. Journal of applied psychology, 23(5), 565-578. https://doi.org/10.1037/h0057079

Trapmann, S., Hell, B., Weigand, S., \& Schuler, H. (2007). Die Validität von Schulnoten zur Vorhersage des Studienerfolgs-eine Metaanalyse. Zeitschrift für pädagogische Psychologie, 21(1), 11-27. https://doi.org/10.1024/1010-0652.21.1.11

Troche, S., Mosimann, M., \& Rammsayer, T. (2014). Die Vorhersage des Studienerfolgs im Masterstudiengang Psychologie durch Schul-und Bachelorstudienleistungen. Beiträge zur Hochschulforschung, 36(1), 30-45. 10.7892/boris.65074

Weimar, D., Schauberger, M., Borowski, S., \& Prinz, J. (2017). Selektionseffekte von Zulassungstests an Universitäten. Betriebswirtschaftliche Forschung und Praxis, 69, 694-716.

Zwick, R. (2002). Fair game?: The use of standardized admissions tests in higher education. Psychology Press. 